\title{
Species multiply as Earth heats up
}

\section{Biodiversity increases with gentle warming.}

\section{Richard Lovett}

03 September 2012

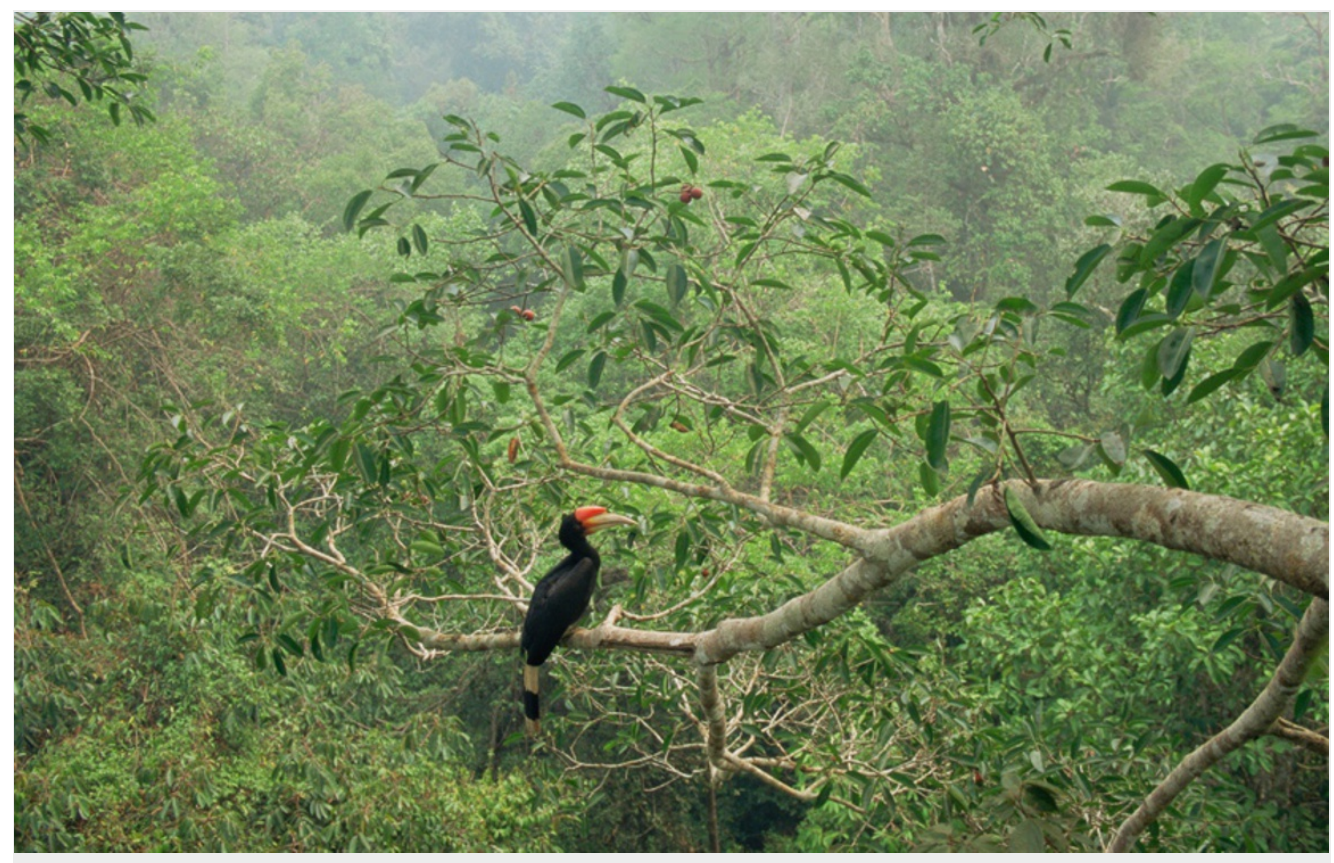

T. Laman/naturepl.com

The tropics are hotbeds of biodiversity — as, it seems, were warm periods in Earth's history.

Rather than kicking off the expected cycles of extinction, periods of warming in Earth's history were accompanied by increased biodiversity, according to a report published this week. But this does not mean that the mass extinctions that are taking place today, with Earth warming at an unprecedented rate, will be reversed in future.

Researchers examined the number of known families of marine invertebrates, as well as sea-surface temperatures, over the course of 540 million years of Earth's history ${ }^{1}$. They found that when temperatures were high, so was biodiversity. When temperatures fell, biodiversity also declined.

The results contradict previous work, including findings from lead author Peter Mayhew's group ${ }^{2}$, that reported an inverse correlation between high temperatures and biodiversity.

The reason for the about-face, says Mayhew, an evolutionary ecologist at the University of York, UK, is that the earlier work measured fossil diversity by tallying the first and last appearances of each group of species, then assuming that the creatures existed only during the intervening years. This might sound logical, but overlooks the fact that some geological periods are better studied than others.

To correct this, the new study looked only at the well-sampled periods. And, instead of interpolating organisms' presence from origination and extinction dates, it merely tallied species groups present during each period.

Even so, given that climate change is generally viewed as disruptive, Mayhew admits it was a "big surprise" to find that eras of warming were accompanied by increases in biodiversity. The work also provided a solution to another puzzle, Mayhew says. Tropical ecosystems are known to be Earth's most diverse, and the tropics would be expected to expand during warm eras. Yet in the past these eras were thought to be species-poor compared with cooler ones. The new results resolve that contradiction.

\section{Speed kills}

Warming produces both extinctions and originations, and in the past the originations of new species have outstripped the loss of old ones, says Mayhew. But this does not mean that today's climate change will be beneficial. 
"The rate of change is very important," Mayhew says. For diversity to rise, he explains, new species need to evolve. And that takes between thousands and millions of years - much slower than the rate at which extinctions are likely to occur with today's rapid change.

Scott Wing, a palaeobiologist at the Smithsonian Institution in Washington DC, agrees. "This article has nothing to say about the effects of global warming at any timescale of interest to most humans," he says. But he adds, "this is definitely of interest to evolutionary biologists, palaeontologists and ecologists seeking to understand very broad patterns of diversity".

However, Shanan Peters, a palaeobiologist at the University of Wisconsin-Madison, isn't so sure the paper is noteworthy. Its primary result, he points out, is to overturn Mayhew's own prior finding and bring the long-term diversity results into line with ecological common sense. "Palaeobiologists and climatologists have long referred to warm intervals as 'climate optima'," he notes, "precisely because it is during such times that palm trees and alligators inhabit the Arctic and life appears to be diverse and flourishing."

More interesting, he says, will be the next generation of results, when palaeobiologists turn their attention to major climate transitions, such as that which may be occurring now.

Mayhew agrees that focusing in on such transitions is the next step. "The time periods we're really interested in now," he says, "are decades and hundreds of years — at maximum 1,000 years."

"You can't get that kind of detail by looking into the deep past," he says. "If you want to know how temperature change is affecting things on that timescale, you're going to have to look at the more recent fossil record."

Nature | doi:10.1038/nature.2012.11350

\section{References}

1. Mayhew, P. J., Bell, M. A., Benton, T. G. \& McGowan, A. J. Proc. Natl Acad. Sci. USA http://dx.doi.org/10.1073/pnas.1200844109 (2012).

2. Mayhew, P. J., Jenkins, G. B. \& Benton, T. G. Proc. R. Soc. B 275, 47-53 (2008). 